\title{
Imagens do inconsciente visível em tramas de comunicação e violência
}

\author{
O sonho é a tentativa de satisfazer um desejo \\ (Freud) \\ Aprenda a viver, descanse quando morrer. Tudo \\ que você precisa está dentro de você \\ (Tyler Durden; Clube da Luta)
}

\section{RESUMO}

O texto traz uma análise do filme "Clube da Luta", em três fases distintas do conflito interno do personagem principal, à partir da perspectiva filosófica de Nietzsche e psicanalítica de Freud. O foco se dá no âmbito da comunicação, cinema e cibercultura. Propõe a aliança entre imaginário do inconsciente visível com o próprio imaginário social, por meio de processos de comunicação das relações de poder que culminam em violência hooligan nos embates do inconsciente com o superego, bem como na própria configuração disciplinar do Clube da Luta.

\section{PALAVRAS-CHAVE}

comunicação

inconsciente visível

cinema

\begin{abstract}
The text provides an analysis of the film "Fight Club" in three distinct phases of the internal conflict of the main character, from Nietzsche's philosophical perspective and Freud's psychoanalytic. It proposes an alliance between the visible imaginary of the unconscious with the social imaginary, through processes of communication based on power relations that culminate in hooligan violence in the collisions of the inconscious with the superego as well as in the discipline configuration of the Fight Club.
\end{abstract}

\section{KEY WORDS}

communication

unconscious

cinema

\section{Francisco Menezes Martins}

Professor e pesquisador do mestrado em Comunicação e Linguagens da UTP/PR/BR e Professor do Curso de Comunicação/Feevale/RS/BR frqnciscomenezes2004@yahoo.com.br

\section{Lívia Meimes}

Mestrando do Programa de Pós-Graduação em Comunicação Social da PUCRS/RS/BR

livia_meimes@yahoo.com.br
Das possibilidades de abordagem da alma humana e sua complexidade interpretativa e comunicativa, o presente artigo propõe a aliança nietzschiana com aspectos sociológicos da psicanálise freudiana e, a partir de perspectivas teóricas do atual e do cotidiano, do consumo e da cultura liberal.

Os verbos que conjugam a posse e a existência parecem, cada vez mais, indissociáveis no âmbito de uma cultura de mercado que tem como religião, seu próprio do modo de vida. A proposta é enlaçar os conflitos surgidos no embate entre inconsciente e ego e sua exteriorização comunicacional. Em caminho inverso é contornar os valores humanos como pressão exterior para a incorporação da moral, culpa, recalque e neuroses. Assim, entende-se que a comunicação ou a falta dela, problematizam as percepções de mundo ao estarem em todo o processo. A medida dos movimentos é visualizada na consciência, levando em conta que:

a consciência não faz parte realmente da existência individual do ser humano, mas antes naquilo que nele é natureza comunitária e gregária (...)cada um de nós, com toda vontade que tenha de entender a si próprio da maneira mais individual possível, de 'conhecer a si mesmo', sempre traz à consciência justamente o que não possui de individual, o que nele é 'médio' - que nosso pensamento mesmo é continuamente suplantado, digamos, pelo caráter da consciência - pelo 'gênio da espécie' que nela domina - e traduzido de volta para a perspectiva gregária (Nietzsche, 2004, pp.249-250).

Produções cinematográficas como o "Clube da Luta", projetam seus discursos para além da grande tela e se convertem em "totens" (Maffesoli, 1995), permanecendo latentes no imaginário contemporâneo. Assim como "Laranja Mecânica", "Assassinos por Natureza", "Kill Bill" e "Um dia de fúria", entre outras, são consideradas obras de culto da pós-modernidade, que inscrevemse, aqui, no presente texto, como um estado de "pós orgia": "O momento explosivo da modernidade, o da liberação política, liberação, sexual, liberação das forças produtivas, liberação das forças destrutivas, liberação da mulher, da criança, das pulsações inconscientes..." (Baudrillard, 2004, p. 9).

Tratam de conflitos internos da alma humana e de sua relação externa com a sociedade: "a psicanálise tomou como tema a mente individual, mas, ao fazer investigações sobre o indivíduo, não podia deixar de tratar da base emocional da relação dele com a sociedade" (Freud, 1974, p. 223). 
Os filmes se sucedem, pois esses argumentos demonstram a quase impossibilidade de fuga do homem diante de seus próprios espelhos. "Vivemos na reprodução indefinida de ideais, de fantasmas, de imagens, de sonhos que doravante ficaram para trás e que, no entanto, devemos reproduzir uma espécie de indiferença fatal" (Baudrillard, 2004, p.10).

O presente artigo tem como objetivo explorar não apenas um filme, mas um imaginário que liga o interior da alma, neste caso, com uma formação tribal dentro da própria obra, além de reverberações nas práticas da cibercultura.

\section{Da relação de poder e} dominação entre a negação da vida e vontade de afirmação (Nietzsche, 2004) o personagem de Norton faz surgir, na visibilidade exterior de sua

\section{própria neurose, um vendedor de sabão feito com gordura}

\section{humana.}

"Clube da Luta", ou "Fight Club", com direção de David Fincher (1999) é uma fábula em que

O intenso sentimento de culpa, que domina tantas neuroses constitui uma modificação social da ansiedade neurótica. Por outro lado, a psicanálise demonstrou plenamente o papel desempenhado pelas condições e exigências sociais como causadores de neurose. As forças que, operando desde o ego, ocasionam a restrição e a repressão do instinto devem fundamentalmente sua origem à submissão às exigências da civilização (Freud, 1974, p. 224).

Não há linha de fuga diante da pressão contemporânea. Em seus estudos sociológicos, Freud nos mostra uma psicanálise indissociável das práticas sociais. “O que hoje é um ato de coibição interna foi outrora externa, imposto, talvez, pelas necessidades do momento. Da mesma maneira, o que hoje se aplica a todo indivíduo em crescimento como uma exigência externa da civilização, poderá um dia tornar-se uma disposição interna à repressão" (Freud, 1974, p. 224).

Além de neurótico, o personagem Jack (vivido pelo ator Edward Norton) é consumista ao extremo. Compra qualquer coisa útil ou inútil, online ou por telefone, a qualquer hora do dia. Sofre de insônia por causa da impotência existencial. Devora catálogos de móveis e utensílios em geral. Coleciona objetos que nunca consome. $\mathrm{O}$ ato de comprar equivale ao prazer predatório. Acalma e soluciona temporariamente as frustrações profissionais e, principalmente, interiores. De alguma forma, o prazer da conquista escapa da guerra e da caça e cai nas práticas de consumo:

Comprar e vender são agora comuns, tal como a arte de ler e escrever; cada qual se exercitou nisso, mesmo não sendo comerciante e pratica diariamente essa técnica. Assim como outrora, os seres humanos eram mais selvagens, cada um era caçador e exercitava, dia após, dia, a técnica da caça. (...) Ao deixar de ser necessária, torna-se luxo e capricho. $\mathrm{O}$ mesmo poderia suceder algum dia com a atividade de comprar e vender. Podemos imaginar condições sociais que não se compra e vende, em que é gradualmente perdida a necessidade dessa técnica: talvez, então, pessoas menos sujeitas à lei das condições gerais permitam-se comprar e vender como um luxo da sensibilidade. Só então o comércio adquiriria nobreza, e os nobres talvez se dedicassem a ele de tão bom grado como a guerra e à política até $o$ momento: enquanto a apreciação da política poderia ter mudado completamente. Já agora ela está deixando de ser ofício do homem nobre, e é possível que ela venha a ser considerada tão comum, que seja posta sob a rubrica de "prostituição do espírito", como tudo o que se escreve para os partidos e jornais (Nietzsche, 2001, p.80).

É quando uma geração abandona a vocação guerreira e disponibiliza altas doses de energia pessoal e coletiva em cultuar o consumo no extremo da religiosidade servil, em plena "Servidão Voluntária" (Baudrillard, 1995) ou formando uma "Geração de Senhoritos" (Ortega y Gasset, 1993).

Em outras palavras:

Daí o paradoxo da era pós-moralista: quanto mais se manifestam os desejos de autonomia individualista, mais as ações morais de generosidade são impulsionadas, estimuladas pelo exterior. Quanto mais há exigência de autogoverno, mais a vida moral é tributária de palavras, de imagens, de mensagens exteriores a nós mesmos (Lipovetsky, 2003, p.29)

Da relação de poder e dominação entre a negação da vida e vontade de afirmação (Nietzsche, 2004) o personagem de Norton faz surgir, na visibilidade exterior de sua própria neurose, um vendedor de sabão feito com gordura humana, Tyler Duren (Brad Pitt), seu superego. Neste ponto vale ressaltar a questão do consumo de qualquer resíduo orgânico, social, industrial ou digital 
pela própria sociedade das práticas de consumo.

Reciclar a gordura extraída de pacientes obesos que se submeteram à cirurgia de lipoaspiração, é uma ácida crítica ao canibalismo estético e consumista da cultura dos Estados Unidos, como pólo de irradiação, mas também de todo o Ocidente, que é atingido por contágio. Pela "virulência dos signos" (Baudrillard, 2004).

Negação contínua, ressentimento, recalque. Ao longo da película, o inconsciente se torna visível, superego dissociado, mas incorporado como imagem. Três pessoas dentro de um corpo. Triângulo da própria alma.

O processo se dá em três fases:

1 A primeira fase está dividida. Na primeira parte do filme, o personagem está Perdido de si e do mundo. É inferior e fraco. Seu padrão de Consumo é compulsivo ao extremo, atuando como religião. Insônia sem cura, culpado por si e por não ter prazer duradouro após comprar tudo.

Há, então, uma mudança na maneira de Jack lidar com o conflito de seu inconsciente com seu superego. Parte para um tipo de voyeurismo sádico, interação com o inferno existencial de grupos de doentes perto da morte. Suicídio em potência de si e de seu próprio recalque.

$2 \mathrm{Na}$ segunda fase, há a majoritária influência do superego na comunicação existencial com o mundo exterior. Tyler diz que as coisas que nos pertencem acabam tomando conta de nós. Só depois de perder tudo é que ficamos livres para fazer qualquer coisa (Tyler-Durden).

$\mathrm{O}$ inconsciente parece render-se à força. O inverso de si mesmo predomina. Surge Tyler, o dominador, dogmático, líder, superior, forte. O superego traz filosofia de força à impotência existencial de Jack:

Você abre a porta e entra

Está dentro do seu coração

Imagine que sua dor é uma bola de neve que vai curar você

Esta é sua vida

É a última gota pra você

Melhor do que isso não pode ficar

Esta é sua vida

Que acaba um minuto por vez

Isto não é um seminário

Nem um retiro de fim de semana

De onde você está não pode imaginar como será o fundo

Somente após uma desgraça conseguirá despertar Somente depois de perder tudo, poderá fazer o que quiser

Nada é estático

Tudo é movimento

E tudo esta desmoronando

Esta é sua vida

Melhor do que isso não pode ficar

Esta é sua vida

E ela acaba um minuto por vez

Você não é um ser bonito e admirável
Você é igual à decadência refletida em tudo

Todos fazendo parte da mesma podridão

Somos o único lixo que canta e dança no mundo

Você não é sua conta bancária

Nem as roupas que usa

Você não é o conteúdo de sua carteira

Você não é seu câncer de intestino

Você não é o carro que dirige

Você não é suas malditas calças

Você precisa desistir

Você precisa saber que vai morrer um dia

Antes disso você é um inútil

Será que serei completo?

Será que nunca ficarei contente?

Será que não vou me libertar de suas regras rígidas?

Será que não vou me libertar de sua arte inteligente?

Será que não vou me libertar dos pecados e do perfeccionismo?

Digo: você precisa desistir

Digo: evolua mesmo se você desmoronar por dentro

Esta é sua vida

Melhor do isso não pode ficar

Esta é sua vida

e ela acaba um minuto por vez

Você precisa desistir

Estou avisando que terá sua chance (Tyler Durden).

O conflito Jack/Tyler encontra na dor a forma de resolução, e no sangue, a forma de purificação. Em razão do próprio título, as luzes da mídia e o próprio imaginário da "após a orgia" centraram nesta parte da obra, suas maiores atenções. O clube surge como exteriorização, imaginário tribal e organização interna digna da Sociedade Disciplinar (Foucault, 1983). Em termos de práticas da cibercultura nas redes sociais, como orkut ou my space, e potencializados pelas próprias cenas do filme no youtube.com, as cenas de luta, mas principalmente, as regras, como comando de voz em nome do segredo, são cultuadas:

As 8 regras do Clube da Luta

1. Você não fala sobre o Clube da Luta

2. Você não fala sobre o Clube da Luta

3. Quando alguém gritar "pára!", ficar no chão ou desmaiar, a luta acaba

4. Somente duas pessoas por luta

5. Uma luta de cada vez

6. Sem camisa, sem sapatos

7. As lutas duram o tempo que for necessário

8. Se for a sua primeira noite no clube da luta, você tem que lutar

Chama a atenção a repetição das regras 1 e 2 como forma neurótica de negar a existência interna de algum segredo a partir de sua comunicação. A plenitude da cisão entre oculto e revelado. $\mathrm{O}$ mundo interior, ainda que na fronteira da alma e da tribo, permanece intocado, 
escondido, intocável em seus rituais e purificante como exorcismo coletivo.

As demais regras dizem respeito à regulação interna do clube. São geradoras de imaginário hooligan e espalham a idéia de que o filme é não apenas violento, mas plataforma de lançamento para casos ocorridos de violência física e social, como nos Estados Unidos e no Brasil, quando um jovem que assistia ao filme em um shopping center de São Paulo, tornou-se um serial killer de apenas uma cena, quando começou a disparar com uma metralhadora dentro da sala escura. O detalhe da dissociação hipodérmica argumentada é que não aparecem armas de fogo ao longo do filme. Seria um símbolo fálico dispensável, avançando nas hipóteses freudianas, dado que o superego de Jack era pródigo neste aspecto, o filme traz um triângulo amoroso imaginário entre uma mulher, mais o inconsciente e o superego de um mesmo homem. Jack sofria de ciúmes de si mesmo e via a si mesmo, na imagem de Tyler, enquanto fazia sexo com sua namorada.

3 A terceira fase é definitiva:

"Somente após uma desgraça conseguirá despertar Somente depois de perder tudo, poderá fazer o que quiser

Nada é estático

Tudo é movimento

E tudo esta desmoronando

Esta é sua vida

e ela acaba um minuto por vez"

(Tyler Durden)

Com o processo crescente, que culmina com o ego implodindo como os edifícios da cena final.

Desde que se pensa, se enfrenta necessariamente uma linha onde estão em jogo a vida e a morte, a razão e a loucura, e essa linha nos arrasta. Só é possível pensar sobre esta linha de feiticeira, e digase, não é forçosamente perdedor, não se está obrigatoriamente condenado à loucura ou à morte (Deleuze, 2004, p.129).

O clube da luta é uma zona da alma onde os demônios interiores se enfrentam quase até a morte. Potência da pulsão de morte. Simulacro de destino. As regras impedem a morte, assim como sua revelação enquanto imaginário de grupo e como metáfora da relação com o inconsciente e o superego.

Síntese do Processo silencioso e invisível que acompanha o personagem desde o início do filme. A violência do conflito acompanha as fases de voyeur do mundo por meio do consumo, interação com a dor de outros e a fundação do clube como solução para a guerra interior que se torna tribo de rituais. Sangue e ferimentos como purificação e alívio mamecos

\section{REFERÊNCIAS}

BAUDRILLARD, J. A Transparência do Mal. São Paulo. Papirus. 2004.

_. El Crímen Perfecto. Barcelona. Anagrama. 1995.

DEBORD, G. A Sociedade do Espetáculo. Rio de Janeiro. Contraponto. 1997.

DELEUZE, G. Conversações. São Paulo. Editora 34. 2004.

FOUCAULT, M. Vigiar e Punir. Petrópolis. Ed. Vozes. 1983.

FREUD, S. O Futuro de Uma Ilusão, O Mal Estar na Civilização e outros trabalhos. Rio de Janeiro. Imago Editora. 1974.

Totem e Tabu e outros Trabalhos. Rio de Janeiro. Imago Editora. 1974b.

LIPOVETSKY, G. Metamorfoses da Cultura Liberal. Porto Alegre. Sulina. 2003.

MAFFESOLI, M. A Contemplação do Mundo. Porto Alegre. Artes \& Ofícios. 1995.

. O Conhecimento Comum. Porto Alegre. Sulina. 2007.

NIETZSCHE, F. A Gaia Ciência. São Paulo. Cia das Letras. 2004.

ORTEGA Y GASSET, J. La rebelión de las Masas. Madrid. Espasa Calpe, 1993. 